Article

\title{
A Study on Soil and Groundwater Pollution Remediation of the Surrounding Real Estate Prices and Tax Revenue Impact
}

\section{Chia-Nung Li ${ }^{1, *}$, Chien-Wen Lo ${ }^{2}$, Wei-Chiang Su ${ }^{3}$ and Tsung-Yu Lai ${ }^{3}$}

1 Department of Natural Resources, Chinese Culture University, Taipei 11114, Taiwan

2 Department of Leisure and Recreation Administration, MingChuan University, Room P209-7, Taipei 33348, Taiwan; E-Mail: chienwen@mail.mcu.edu.tw

3 Department of Land Economics, National Chengchi University, Room 270603, Taipei 11605, Taiwan; E-Mails: 100257502@nccu.edu.tw (W.-C.S.); tylai@nccu.edu.tw (T.-Y.L.)

* Author to whom correspondence should be addressed; E-Mail: ljn@ulive.pccu.edu.tw; Tel.: +886-2-2861-0511 (ext. 31434).

Academic Editors: Vincenzo Torretta and Fausto Cavallaro

Received: 17 June 2015 / Accepted: 28 October 2015 / Published: 3 November 2015

\begin{abstract}
To see whether the surrounding real estate price after soil and groundwater pollution remediation will revert to the level before the risk of implicit pollution, this paper uses research methods, such as the hedonic price method and contingent valuation method for analysis. The results of empirical analysis reveal that the hedonic price method will be restricted by trade cases around pollution sites. In view of this, it proposes using the contingent valuation method and consumers' viewpoints for the analysis. Empirical results show that after pollution remediation the respondents are willing to pay an average of $\$ 1168$ per square meter, which is slightly higher than the current price of $\$ 1059$ per square meter with an increase of about $10 \%$. Therefore, prices will recover after remediation at least to the level of the surrounding area.
\end{abstract}

Keywords: soil and groundwater; hedonic price method; willingness to pay; pollution remediation 


\section{Introduction}

Soil and groundwater pollution not only impacts the normal use of the land but also may endanger nationals' health as well as the surrounding living environment. For this reason, apart from impairing the value of real estate on individual polluted land, pollution may result in external effects and affect the price of surrounding real estate.

Take a domestic case, for example. Guoling Gas Station in Zhongli City, Taoyuan County, where oil and gas leaked in August 2009, was announced as a groundwater pollution control site. In 2010, when the residents here applied for the mediation of compensation for damages to the government of Taoyuan County, a real estate assessment mechanism was launched for the first time. The assessment result showed that this community did not have a trade record to directly prove the impairment of real estate's exchange value, but according to the trading price of real estate in adjacent regions, the expense of pollution, clearing or remediation aside, only psychological factors resulted in a depreciation rate of $7.5 \%$ in real estate. At last, it was adjudicated that the gas station shall compensate for surrounding land owners the impairment of real estate depreciation. According to this case, it is widely realized that a pollution site has an impact upon surrounding real estate prices at present.

Compared with hazards caused by pollution, the benefit brought by pollution remediation is to go back to the state before pollution, including the changes to health, environment, crop, water quality and the value of real estate [1]. However, according to the adjudication result of the case of Guoling Gas Station in Zhongli City, Taoyuan County, even if a pollution event is ascertained and legal disposal or remediation is finished, the public cannot restore their psychological state to that before the pollution. In other words, the existence of the accomplished fact will still have some potential impact upon the applicants' real estate value. Nevertheless, based on questionnaires, Jackson [2] considered that as for real estate that used to be polluted but has been remediated, its impact of pollution upon the transaction price disappears. Therefore, due to the lack of more explicit empirical analysis of the impact upon surrounding real estate value before and after pollution remediation, and if pollution remediation contributes to restoring the impairment of value, including the degree, time, and relevant conditions, this paper plans to make an exploration in this regard.

At present, the government specifies pollution sites to avoid the continuous use of land, but remediation and reuse appears to be slow. In particular, the vacancy of polluted land actually results in the waste of land resource, the reduction of local taxation [3], as well as surrounding residents' psychological pressure and the impairment of housing prices. For this reason, it is indeed essential and pressing to actively drive the remediation of polluted land. According to the view of environmental justice, liable polluters should take the responsibility for remediation and compensation, but their willingness for remediation must be determined in line with the analysis result of the remediation benefit. Therefore, for effective pollution remediation, it is of great necessity to promote economic benefit and reduce uncertainty after remediation, so as to endow private sectors with economic incentive for active remediation.

A good knowledge of the remediation effect of pollution sites will contribute to assessing the feasibility, proper scale, and schedule of the remediation plan, for the purpose of more effectively allocating financial resources. In addition, the benefit analysis of pollution remediation plans can be taken as private sectors' investment incentive so as to encourage them to actively devote themselves to remediation and cooperate with local government's macro long-term urban redevelopment, which will 
contribute to the sustainable development of cities and resources. Hence, this paper collects relevant literatures on value and revenue caused by soil and groundwater pollution and collates pollution status, influence degree, and assessment method, laying a foundation for follow-up situation-setting and empirical analysis. Moreover, by presenting related redevelopment cases overseas, it probes into relevant economic benefit and relevant financial tools. The hedonic price method, case analysis method, and willingness-to-pay method are used to demonstrate the impact upon real estate price and tax increment before and after pollution remediation. Additionally, by referring to America's tax increment financing system (TIF), the paper explores economic benefit recycling of real estate increment and tax increment caused by pollution remediation and land redevelopmen, and assesses the feasibility of taking it as the revenue source of soil and groundwater pollution remediation or the financial resource of brown field redevelopment, thus providing reference for future policy making.

\section{Literature Review}

Industrial land use, agricultural land use, and illegal land abandonment may cause soil and groundwater pollution, thus endangering citizens' health and impacting living environment, ecological resources, land utilization, regional development, etc. In particular, land pollution not only impacts the land itself, but also has external impact upon surrounding land, to become one of the factors influencing the characteristics of surrounding house prices. However, despite the serious land pollution, discussion on the value of polluted land can be scarcely found in Taiwan [4]. Particularly, pollution remediation contributes to recovering original utilization value of land, but relevant literatures about the actual recovery degree, range, and time point after the remediation of various pollution sites can hardly be found at present.

\subsection{Value Impairment to Polluted Site}

The impact of pollution upon real estate value can be generally divided into two aspects. First of all, a polluted site causes value impairment to itself. Current scholars such as Jackson [5], Lin Ziqin, and Chen Zhenwei [4] mainly focus on the valuation of this polluted site. Other scholars use the case study method [6-8], and the situation analysis method $[9,10]$ for analysis.

\subsection{Value Impairment to Real Estate near the Polluted Site}

In addition, a polluted site's impairment to the value of surrounding real estate is always affected by negative external factors. The psychological impact for being close to the polluted land is generally called value impairment impact of stigma. Both Patchin [11] and Mundy [12] believed that the following factors influencing the price of stigma: disposal cost, implicitness, risk, degree of trouble, public liability, land utilization confinement degree, type of real estate, etc. Based on a questionnaire survey, Jackson [2] pointed out that at different time points before and after pollution remediation, the risk perceived by respondents' was different and most respondents believed that the risk will reduce as general land after remediation. However, this literature does not mention this effect can be achieved, in what situation, at what time. Thus, this paper is to discuss the change of real estate price at three time points, including before pollution remediation and after pollution remediation, so as to make up for the deficiency of past 
literatures. There are over a dozen different real estate techniques used to determine the effects of contamination and other proximity influences on property values, and they can be broadly characterized into two groups: those examining past market outcomes (revealed preferences), like hedonic regression analysis; and those that ask respondents what might happen (stated preferences), like contingent valuation [13]. In most present literatures [14-19], the hedonic price model analysis is adopted to research the influence of surrounding real estate values. The empirical results reveal that a soil and groundwater pollution site impairs the value of surrounding real estate by more than $10 \%$. Although its impairment degree is not so high as that of polluted land, the value still drops considerably. Not only does the reduced price of polluted land cause the reduction of land tax, but also the government's special deduction and exemption to polluted land forces the government to face the loss of tax [20]. This is also quite an important issue when the present government is faced with financial embarrassment.

\subsection{Benefit of Pollution Remediation and Its Impact upon the Value of Surrounding Real Estate}

The benefit of a polluted site after remediation, mainly from the improvement of environmental quality, can be divided into direct benefit and indirect benefit, market benefit and non-market benefit. Remediation will result in a benefit change to health, environment, crop, water quality, and real estate value [1]. However, current domestic research on the social cost-benefit analysis of soil and groundwater pollution focus on the pre-evaluation when the method of pollution construction is selected, but cost-benefit analysis has not yet been applied to ex ante pre-evaluation and ex post impact evaluation of pollution control policies [1]. In terms of economic benefit after pollution remediation, completing polluted land remediation not only makes the price of polluted land and surrounding real estate rise again, but also enhances government tax revenue, further drives local industrial activities, and offers more employment opportunities because of the redevelopment and reutilization of polluted land [20]. For this reason, in recent years, foreign literatures have begun to explore if pollution remediation contributes to the enhancement of house prices [21]. For instance, the empirical analysis results of the remediation of hazardous wastes sites reveal that the value will increase by an average of $14.7 \%$ after the remediation. Chicago Metropolitan Agency for Planning used to entrust a consultant company [22] to analyze the benefit of polluted land remediation. The report takes six polluted lands of different types, sizes, and locations, for example, to respectively compare the price change of polluted land and surrounding land before and after the remediation. It is discovered that the price of polluted land rose by 1.3-8.3 times and that of surrounding land rose by 1.06-2.52 times after the remediation. Furthermore, the empirical results of Kohlhase [15] also show consumers act on the information that is available to them, and that government and private efforts to clean-up toxic wastes can enhance housing values. Dale et al. [17] find that property values around the smelter will be negatively affected and the prices of residential properties rebound after the stigmatized location is cleaned up. Therefore, the value of surrounding real estate will rise when a contaminated site is remediated.

\subsection{Benefit of Pollution Remediation and Its Impact upon the Value of Surrounding Real Estate}

Due to tremendous expense of pollution remediation and uncertain benefit of land value after the remediation, polluted land is always left unused. For example, some polluted sites in metropolises or densely populated areas have impacts upon the appearance of the city and surrounding living 
environment, but due to the tremendous capital and long time spent on remediation, as well as the limitation to the control over the remediation site and relevant regulations for land prohibition disposal, the value and marketability of land are weakened, the cost of remediation is high, but revenue is uncertain, thus possibly affecting the polluters's willingness for pollution remediation. In particular, government has not provided standards and economic incentives related to the redevelopment plan of polluted land; thus, in current domestic research, it is still difficult to arouse developers' willingness to remedy the polluted land by themselves with the benefit of land development.

According to the analysis results of Lin and Qiu [3], 90\% of polluted land is self-remedied land and marginally feasible land (such as gas station, factory, and storage tanks on urban and non-urban land). From the view of pollution remediation and redevelopment, the government should avoid leaving polluted land unused as far as possible but should actively consider how to redevelop and reutilize it. The economic benefit created by redevelopment can attract developers' investment. However, to reach this goal, an evaluation for the benefit of redevelopment should be made first so as to have a mastery of the potential of development. Furthermore, Liu and Qiu's [3] questionnaire survey results reveal that most respondents were inclined to make positive use of the land.

In view of the above urban problems, the government should actively consider how to resolve the vacancy of polluted land. English Partnerships [23] hold that the government can make a plan to turn polluted land into high-value land. Moreover, infrastructure near polluted land can be constructed to improve the overall environment so as to enhance the value of land reutilization [3]. Obviously, regarding the purpose of soil pollution remediation, a common answer of European and American policies is to recreate the value of polluted land [24]. Therefore, the enhancement of land value determines if developers will carry out positive remediation work.

In addition, this research takes the US Atlantic Steel Site Redevelopment Project, Canada Spencer Creek Village, and Quai des Éclusiers as examples for case study. According to the results of the case study, it can be known that the redevelopment of brown fields will create considerable revenues of real estate. The most important key is local government's relevant policies and urban planning, as well as private developers' investment. Without private developers' investment, local government won't have sufficient financial resources, so urban redevelopment cannot be achieved. Thus, that government providing sufficient incentives for attracting developers is one of the critical factors of successful redevelopment of brown fields. In this process, it is quite important to improve the financial mechanism and apply the increment of real estate value and land tax.

An accurate estimate of damages must account for both the time period the site is stigmatized, and the speed and trend of price rebound [18]. The value change expected by this research is shown in Figure 1 as below. When land is polluted, it will result in remediation cost, utilization limitation, stigma impairment and reduction of land value, but the original value can be recovered after pollution remediation (see Jackson's study [25]). However, if overall redevelopment is carried out to promote the redevelopment of urban economy, the value of real estate will be higher than that before pollution, thus contributing to encouraging private developers' active remediation. Furthermore, hedonic price analysis and contingent valuation analysis can be used for demonstration. 


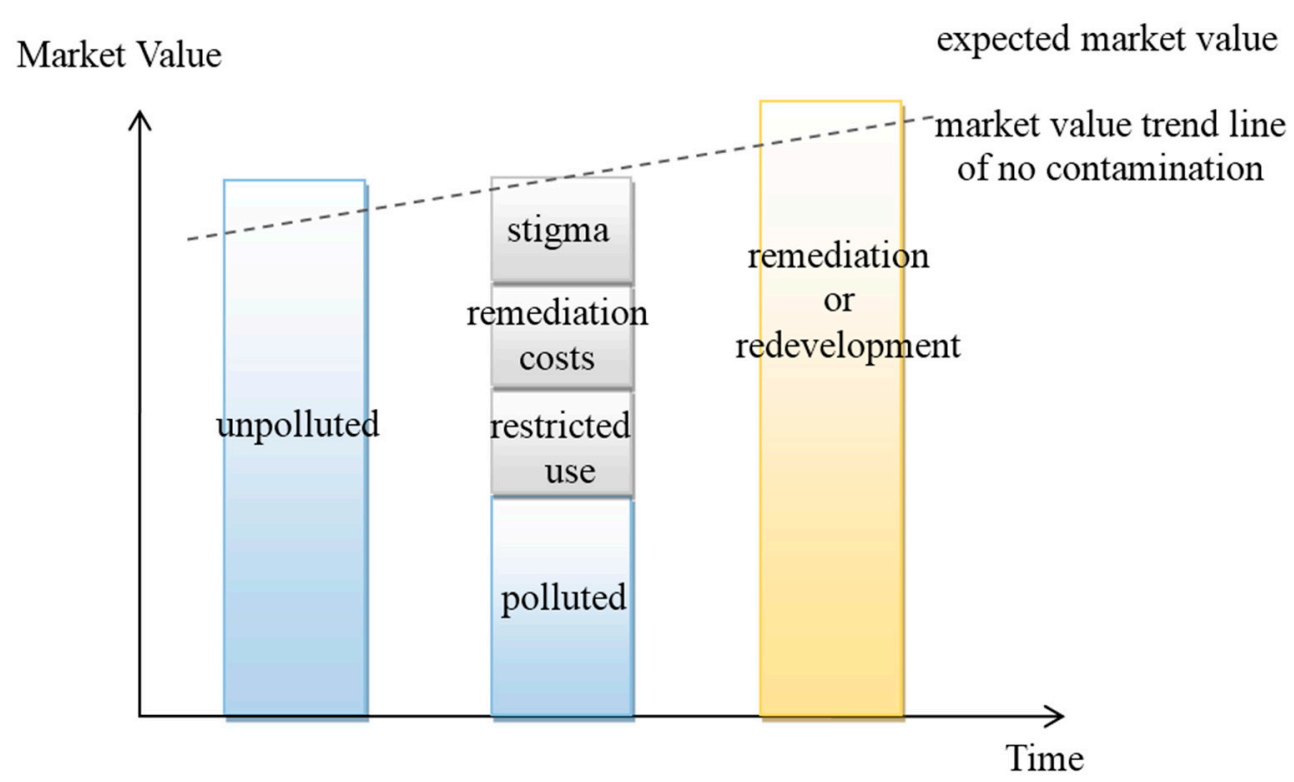

Figure 1. The Change of Land's Market Value before and after Pollution Remediation.

\section{Results and Discussion}

\subsection{Hedonic Price Method}

To clarify if a pollution incident has an impact upon the determination of the actual trading price, this research uses the hedonic price method to analyze the trading price of surrounding real estate in Taoyuan. The hedonic price model is built as follows. The independent variable set contains a wide range of house, neighborhood, community, and environmental variables.

$$
\text { PRICE }=C O N S T A N T+\beta_{1} A G E+\beta_{2} B A R E A+\beta_{3} B U I L D I N G+\beta_{4} F L O O R+\beta_{5} Z O N I N G+\beta_{6} L A R E A+\beta_{7} C O N D I S T
$$

According to regression analysis of the hedonic price model, the relationship between the distance from polluted/remedied land and house price can be determined so as to confirm the sphere of influence. Variables are declared in Table 1 as below.

Table 1. Characteristic Variables Declaration.

\begin{tabular}{lccl}
\hline \multicolumn{2}{c}{ Variable Name } & Variable Declaration (Unit) & $\begin{array}{c}\text { Expected } \\
\text { Sign }\end{array}$ \\
\hline dependent variable & PRICE & Total selling price of real estate (dollars/household) & - \\
\hline & AGE & Age of house (year) & + \\
& BAREA & Floor space per household (square meter, $\mathrm{m}^{2}$ ) & + \\
& BUILDING & Building materials: reinforced concrete $=1 ;$ others $=0$ & + \\
independent variables & FLOOR1 & If it is on the 1st floor: yes $=1$; no $=0$ & - \\
& AFLOOR & Total number of floors (floor) & + \\
& ZONING & Use zoning: residential area $=1 ;$ others $=0$ & + \\
& LAREA & Area of transferred land (square meter, $\mathrm{m}^{2}$ ) & \\
& CONDIST & Straight-line distance between polluted site and real transaction case (meter) & \\
\hline
\end{tabular}


Real transaction data were obtained from a real estate transaction price inquiry service website of the Ministry of the Interior, and cases were searched from January 2011 to March 2014. Regression analysis of hedonic price is conducted in a cross-sectional way to demonstrate the influence of the distance of polluted site on the price of surrounding real estate. The summary statistics are show in Table 2 and the map in Figure 2.

Table 2. Summary statistics for variables used in the hedonic house price model.

\begin{tabular}{cccccc}
\hline Variables & Full Sample & Minimum & Maximum & Mean & Standard Deviation \\
\hline PRICE & 114 & 125.00 & 1050.00 & 296.68 & 154.63 \\
AGE & 114 & 13.00 & 42.00 & 29.21 & 5.29 \\
BAREA & 114 & 25.69 & 220.00 & 26.96 & 8.52 \\
BUILDING & 114 & 1.00 & 1.00 & 1.00 & 0.00 \\
FLOORI & 114 & 0.00 & 1.00 & 0.18 & 0.37 \\
ZONING & 114 & 0.00 & 1.00 & 0.94 & 0.24 \\
LAREA & 114 & 2.84 & 37.19 & 8.48 & 3.96 \\
CONDIST & 114 & 306.00 & 1681.00 & 1167.48 & 359.40 \\
\hline
\end{tabular}

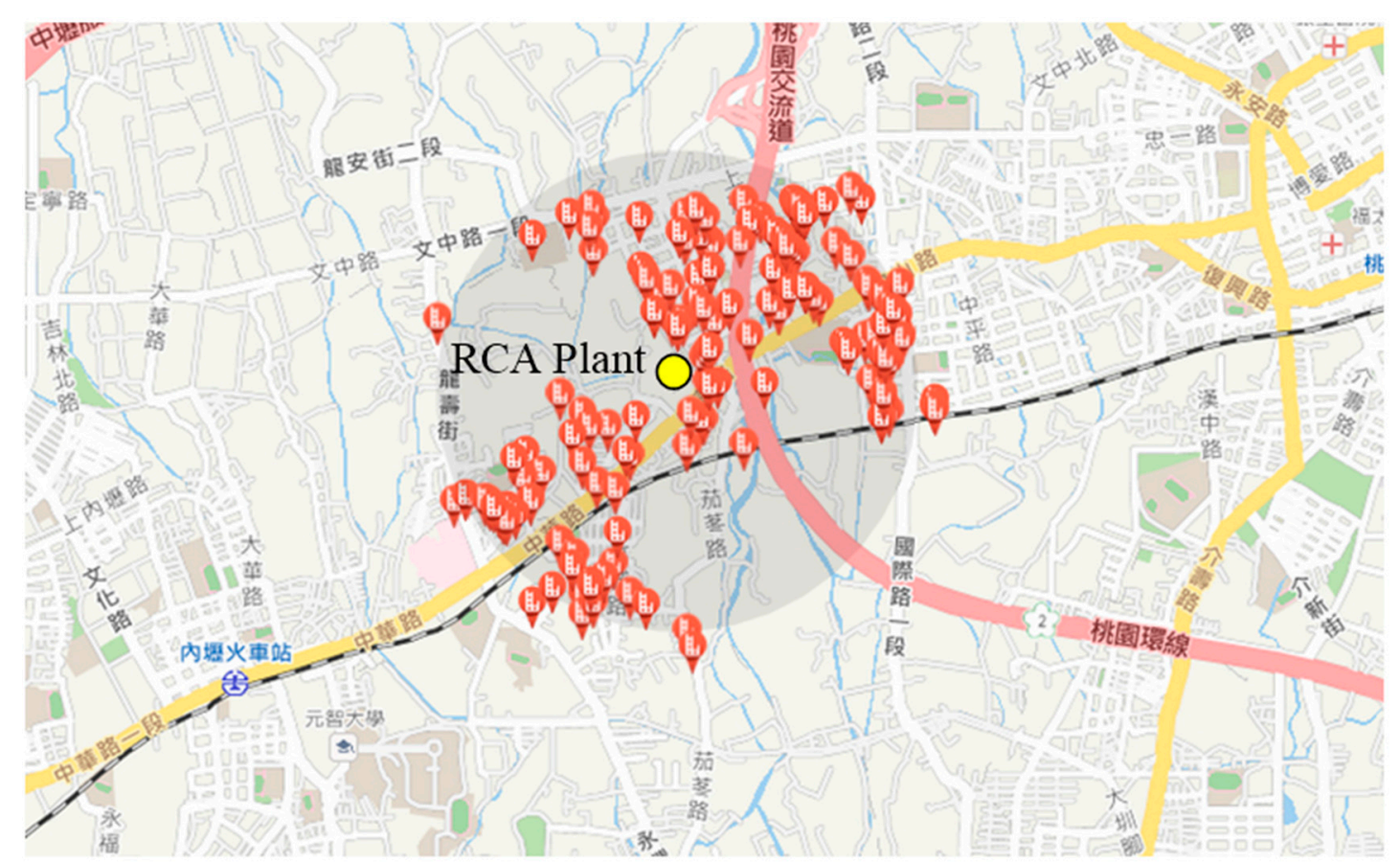

Figure 2. The map of every transaction case.

Take the hedonic price analysis results of RCA Plant in Taoyuan, for example, and the results are show in Table 3. He adjusted R-square of the model is 0.592 , VIF less than 10, and residuals showing normal probability distribution. Although the distance of the polluted site confirms to the expected influence sign, it is not significant. According to the descriptive statistics table, it can be observed that an average distance between transaction cases and the RCA Plant is about $1167.5 \mathrm{~m}$, and the nearest distance is $306 \mathrm{~m}$, which reveals that there are not sufficient surrounding transaction cases for analysis. What is worse, cases near Dongbao Gas Station and Tainan Jinghui Industrial Plant are fewer. Thus, the analysis result of regression model is limited. 
Table 3. Hedonic price analysis result of Taoyuan RCA Plant's polluted site.

\begin{tabular}{|c|c|c|c|}
\hline & $\beta$ Estimated Value & Standard Error & Significance \\
\hline CONSTANT & 131.706 & 87.253 & 0.134 \\
\hline$A G E$ & -3.735 & 1.879 & $0.049 * *$ \\
\hline BAREA & 12.118 & 1.236 & $0.000 * * *$ \\
\hline BUILDING & 120.863 & 24.948 & $0.000 * * *$ \\
\hline FLOOR1 & -83.698 & 38.432 & $0.031 * *$ \\
\hline ZONING & 2.497 & 2.465 & 0.313 \\
\hline LAREA & -0.020 & 0.027 & 0.476 \\
\hline CONDIST & 131.706 & 87.253 & 0.134 \\
\hline
\end{tabular}

Note: $*$ denotes $p<0.1$, ** denotes $p<0.05$, and $* * *$ denotes $p<0.01$.

According to the results of empirical analysis, limited to the number and type of cases near the polluted site, it is difficult to evaluate the actual impact of pollution remediation upon the price of surrounding real estate with the hedonic price method. In fact, the contingent valuation method (CVM) has used when actual selling data is difficult to acquire [26]. As another study shows that the disadvantage of the distance model is that it is likely to be correct only to the extent that the perceived risk declines continuously with distance from the location, that distance model may misspecify the true relationship and cause biased inferences about the role of the remediation policies and the extent of the rebound [18]. Thus, there is much research that used a zonal model with a dummy variable to improve this problem, but our cases are still not enough. Thus, the following will take the CVM and a questionnaire to investigate consumers' willingness to pay (WTP) for the pollution remediation from the consumers (surrounding residents)' perspective, in the hope of demonstrating the influence of pollution remediation on the price and tax increment of surrounding real estate.

\subsection{Contingent Valuation Method, CVM}

In view of the application limit of the hedonic price method, this research proposes using the contingent valuation method (CVM) to evaluate future surrounding areas of polluted site. Unlimited to existing data, the contingent valuation method can directly obtain the price consumers are willing to pay from their demand and directly verify the impact of pollution remediation upon the price of real estate. In addition, this research plans to evaluate if the un-occurred remediation can promote the price of real estate again and then increase the revenue of tax. For this reason, the contingent valuation method is used for the hypothesis of the market situation so as to determine the price consumers are willing to pay (WTP). Whether the elicitation approach uses WTP or willing to accept (WTA) depends on which consumer surplus measure is sought—one dealing with a quantity increase or a quantity decrease [26], or the money or assets are part of their endowment or not [27]. Since our research is about increasing environmental quality and our survey respondents are not confined to the owners of real estate around the contaminated site, we think the correct compensating surplus measure is WTP.

Given that the survey is conducted via questionnaire, it is unable to give respondents an opportunity of repeated price offering. To get the original price in respondents' mind, open inquiry is conducted. However, to avoid respondents' indefinite cognition of surrounding house prices and big differences in 
price, the average unit price in actual transactions of surrounding real estate is provided, so as to help consumers offer a price and get the price they are willing to pay.

Questionnaire samples were mainly residents living near RCA and those in Taoyuan County who were familiar with the surrounding environment. As for the sampling method, questionnaires were distributed near the RCA site, namely, Zhonghua Road and Longan Street. In the process of sampling, passers-by were enquired unremittingly without considering their gender and age. Moreover, households and merchants were investigated as well. If respondents had any doubt, a brief explanation for the purpose of questionnaire survey was given. However, to further analyze the difference in price offering caused by different cognition of the RCA pollution event, the specific situation of RCS pollution was not explained to avoid affecting respondents' willingness to pay.

In the investigation, a total of 500 questionnaires were distributed and 492 valid ones were collected, thus, the response rate reached $98.40 \%$. Table 4 shows the descriptive statistics of the sample of the residents who participate in the CVM survey and a comprehensive analysis is as follows.

Table 4. Summary statistic of participates in the CVM survey.

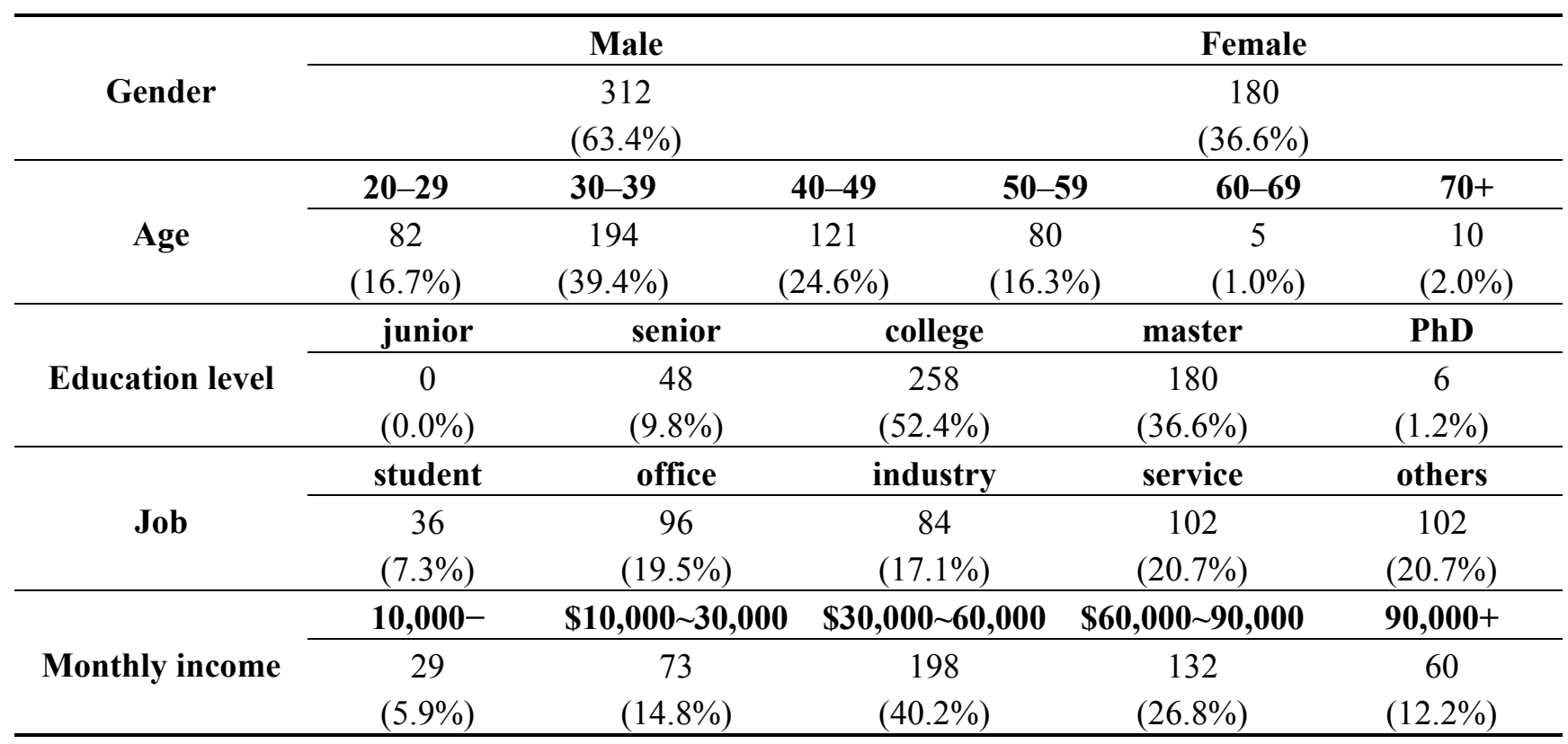

3.2.1. Pollution Remediation Has Positive Influence on the Price of Surrounding Real Estate

In fact, a polluted site often looks like ordinary idle land. Without a good knowledge of the major pollution incident around, it may be unable to reflect the surrounding transaction price, just like the analysis result of the hedonic price mentioned above. However, from the perspective of consumers' psychology of buying a house, the lack of good knowledge of a pollution incident is bound to affect their willingness to pay. According to the results of questionnaire survey, among 89 respondents who had no idea of RCA pollution incident, only seven of them believed that pollution had no impact upon the price of real estate. Thus, it is revealed that respondents believed a pollution incident had an impact upon the price of surrounding real estate, which is in line with the expected hypothesis of this research. As for the problems that if a safety concern can be resolved after remediation, respondents believed that the price would be recovered to the level of the surrounding real estate price and even slightly higher than current 
price of $\$ 1059$ per square meter. In other words, the average price they offered is $\$ 1168$ per square meter with an increase of $10 \%$, which is similar to the research results of related literatures in the past.

\subsubsection{The Price Respondents Were Willing to Pay was Related to Their Monthly Income}

Respondents who obtained more than $\$ 2000$ a month were willing to pay an average of $\$ 1360$ for every square meter after pollution remediation. By contrast, those who earned less than $\$ 2000$ a month were willing to pay less; namely, $\$ 1039$ per square meter, slightly lower than current house price.

\subsubsection{Development Incentives Are Lacked but Concerns Exist in Pollution Remediation}

According to the comprehensive cross-over analysis results of questionnaires, 47 respondents were unwilling to pay any money for surrounding houses after remediation, which reveals the lack of incentive for them. Among these 47 respondents, 35 of them were unwilling to pay for surrounding houses after redevelopment of the RCA site and even paid little attention to the form of redevelopment. Thus, it can be concluded that they were unwilling to buy surrounding houses because they had concerns about pollution remediation. Therefore, it is rather important to confirm and advocate the safety of pollution remediation, only in which way can the utilization of a polluted site be enhanced and surrounding urban development be promoted.

\section{Conclusions}

This research is aimed at exploring the impact of soil and groundwater pollution remediation on the price and tax revenue of surrounding real estate. With the application of the hedonic price method, contingent valuation method, and tax increment fund, conclusions are made as follows.

\subsection{Application Restrictions of Analyzing the Price of Real Estate near Polluted Site with Hedonic Price Method}

This research takes the data of actual transaction prices of real estate around the polluted site for analysis of the hedonic price model. According to the empirical results, we limited to the number and type of cases near the polluted site and as we did not have enough sales data, it is difficult to evaluate the actual impact of pollution remediation upon the price of surrounding real estate with the hedonic price method. In particular, due to the significant factors influencing the transaction price, the non-transparent transaction information, and the fact that the polluted site seems like ordinary idle land, the lack of good knowledge of a major pollution incident may not truthfully reflect the impact of pollution factors upon the price. Thus, the research proposes taking the contingent valuation method and questionnaire to investigate consumers' willingness to pay for the pollution remediation from the consumers' perspective, in the hope of demonstrating the influence of pollution remediation on the price and tax increment of surrounding real estate. 


\subsection{Positive Significant Influence of Pollution Remediation on the Price of Real Estate}

According to the results of WTP analysis, after pollution remediation the respondents are willing to pay an average of $\$ 1168$ per square meter, which is slightly higher than current price of $\$ 1059$ per square meter of surrounding real estate. The result is similar to Jenkins et al. [28]: the average WTP of homes for which the disclosure of lead, zinc, and cadmium contamination and clean-up is required will drop by approximately $30.5 \%$ of the value of the typical home in the area, and a summary finding of Simons, that close-in losses typically were $15 \%-30 \%$ [13]. Furthermore, the results reveal that the combination of pollution remediation promotes the increment of surrounding real estate and the production of relevant tax revenues, enhance overall land utilization in this region, drives regional development, and produces incentives for the private sector's investment.

\section{Acknowledgments}

Special thanks to Zhi-Yuan Yang for discussions. Thanks also to Environmental Protection Administration, Executive Yuan, Taiwan (R.O.C.). Soil and Groundwater Pollution Remediation Fund Management Board for funding our project.

\section{Author Contributions}

This research was designed and written by Chia-Nung Li, Chien-Wen Lo, Wei-Chiang Su, and Tsung-Yu Lai. The data was analyzed by Chia-Nung Li and Wei-Chiang Su. The data analysis is corresponding to Chia-Nung Li. All authors approved the final manuscript.

\section{Conflicts of Interest}

The authors declare no conflict of interest.

\section{References}

1. Environmental Protection Agency of Executive Yuan. Chung-Hua Institution for Economic Research, Review, Adjustment and Planning of Soil and Groundwater Pollution Remediation Expense Collection System; Environmental Protection Agency of Executive Yuan: Taipei, Taiwan, 2012.

2. Jackson, T.O. The analysis of environmental case studies. Apprais. J. 2002, 70, 86-95.

3. Lin, Z.; Qiu, J. Several ideas on the reutilization of polluted land. J. Environ. Land Law Taiwan 2013, 1, 123-138.

4. Lin, Z.; Chen, Z. Risk, stigma and value of polluted industrial land: Inspirations from America's experience. J. Hous. Stud. 2009, 18, 23-44.

5. Jackson, T.O. Methods and techniques for contaminated property valuation. Apprais. J. 2003, 71, 311-320.

6. Page, G.W.; Rabinowitz, H. Groundwater contamination: Its effects on property values and cities. J. Am. Plan. Assoc. 1993 59, 473-482. 
7. Patchin, P.J. Contaminated properties and the sales comparison approach. Apprais. J. 1994, 62, 402-409.

8. Bell, R. The impact of detrimental conditions on property values. Apprais. J. 1998, 66, 380-391.

9. Li, Y.; Huang, Z.; Chen, D. Research on Polluted Land Valuation Method-Take Taijian Anshun Plant's Polluted Area as Example. In Proceedings of the Symposia of the Second National Academic Seminar of Disaster Crisis Management, Taipei, Taiwan, 11-12 April 2002.

10. Li, J. Research on Polluted Land Valuation. Master's Thesis, Land Management and Development Research Institution of Chang Jung Christian University, Tainan, Taiwan, 2008.

11. Patchin, P.J. Contaminated properties-Stigma revisited. Apprais. J. 1991, 59, 167-172.

12. Mundy, B. Stigma and value. Apprais. J. 1992, 60, 7-13.

13. Simons, R.A. When Bad Things Happen to Good Property; Environmental Law Institute: Washington, DC, USA, 2005; pp. 63-112.

14. McClelland, G.H.; Schulze, W.D.; Hurd, B. The effect of risk beliefs on property values: A case study of a hazardous waste site. Risk Anal. 1990, 10, 485-497.

15. Kohlhase, J.E. The impact of toxic waste sites on housing values. J. Urban Econ. 1991, 30, 1-26.

16. Simons, R.A.; Bowen, W.M.; Sementelli, A.J. The effect of underground storage tanks on residential property values in cuyahoga county, Ohio. J. Real Estate Res. 1997, 14, 29-42.

17. Simons, R.A.; Bowen, W.M.; Sementelli, A.J. The price and liquidity effects of UST leaks from gas stations on adjacent contaminated property. Apprais. J. 1999, 67, 186-194.

18. Dale, L.; Murdoch, J.C.; Thayer, M.A.; Waddell P.A. Do property values rebound from environmental stigmas? Evidence from Dallas. Land Econ. 1999, 75, 311-326.

19. Zabel, J.E.; Guignet, D. A hedonic analysis of the impact of LUST sites on house price. Res. Energy Econ. 2012, 34, 549-564.

20. Qiu, J. Exploration on Promoting the Reutilization of Polluted Land. Master's Thesis, Land Economic Faculty of National Chengchi University, Taipei, Taiwan, 2012.

21. Gamper-Rabindran, S.; Timmins, C. Does cleanup of hazardous waste sites raise housing values? Evidence of spatially localized benefits. J. Environ. Econ. Manag. 2013, 65, 345-360.

22. S.B. Friedman \& Company. Fiscal Analysis of Brownfield Redevelopment. Available online: http://www.cmap.illinois.gov/documents/10180/47947/Brownfields+case+study.pdf/7aeeafe6452a-4aa9-b980-50c1714ed54e (accessed on 15 March 2014).

23. English Partnership. Towards a National Brownfield Strategy. Available online: http://image.guardian.co.uk/sys-files/Society/documents/2003/11/06/brownfield.pdf (accessed on 15 March 2014).

24. Huang, Z. Sustainable use of polluted land. Sinotech Eng. Q. 2009, 103, 7-12.

25. Jackson, T.O. The effects of previous environmental contamination on industrial real estate prices. Apprais. J. 2001, 69, 200-210.

26. McLean, D.G. The addition of contingent valuation and conjoint analysis to the required body of knowledge for the estimation of environmental damages to real property. J. Real Estate Pract. Educ. 1998, 1, 1-19.

27. Knetsch, J.L.; Sinden, J.A. Willingness to Pay and Compensation Demanded: Experimental Evidence of an Unexpected Disparity in Measures of Value. Q. J. Econ. 1984, 99, 507-521. 
28. Jenkins-Smith, H.C.; Silva, C.L.; Berrens, R.P.; Bohara, A. Information disclosure requirements and the effect of soil contamination on property values. J. Environ. Plan. Manag. 2002, 45, 323-339.

(C) 2015 by the authors; licensee MDPI, Basel, Switzerland. This article is an open access article distributed under the terms and conditions of the Creative Commons Attribution license (http://creativecommons.org/licenses/by/4.0/). 